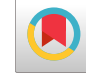

\title{
Long non-coding RNA GHET1 Is Possibly Involved in the Pathogenesis of a Fraction of Breast Cancers
}

\author{
Shaghayegh Sarrafzadeh, ${ }_{1}$ Mohammad Taheri, ${ }^{1}$ Lobat Geranpayeh, ${ }^{2}$ Somayyeh Ghafouri-Fard,${ }^{3}$ and \\ Soudeh Ghafouri-Fard ${ }^{1, *}$ \\ ${ }^{1}$ Department of Medical Genetics, Shahid Beheshti University of Medical Sciences, Tehran, Iran \\ ${ }^{2}$ Department of Surgery, Sina Hospital, Tehran University of Medical Sciences, Tehran, Iran \\ ${ }^{3}$ Department of Community and Preventive Medicine, School of Medicine, Tehran University of Medical Sciences, Tehran \\ "Corresponding author: Soudeh Ghafouri-Fard, Department of Medical Genetics, Shahid Beheshti University of Medical Sciences, Tehran, Iran. Tel/Fax: +98-2123872572, E-mail: \\ s.ghafourifard@sbmu.ac.ir
}

Received 2016 December 04; Accepted 2017 September 30.

\begin{abstract}
Background: Breast cancer is the most frequently diagnosed cancer among women. Although several targeted therapies have been applied for patients with breast cancer, due to its heterogeneous nature, several patients do not benefit from these treatment modalities. Consequently, it is necessary to identify novel markers, which participate in the development of breast cancer. Recently, long non-coding RNAs (lncRNAs) have gained attention in this regard. Among them is lncRNA-gastric carcinoma high expressed transcript 1 (lncRNA-GHET1), whose participation in gastric and bladder cancers have been identified.

Objectives: In the present study, we aimed at identifying IncRNA-GHET1 expression in breast cancer tissues compared with their adjacent non-cancerous tissues (ANCT) in a cohort of Iranian patients.

Methods: We evaluated the expression of GHET1 in 47 samples of invasive ductal carcinoma of breast in comparison with their ANCTs by means of quantitative real time-PCR.

Results: GHET1 has been shown to be up-regulated in $26 \%$ (13 out of 47) breast tumor samples compared with their paired ANCTs. Transcript levels of GHET1 were shown to be associated with body mass index. No other significant association was found between the level of transcripts and patients' clinical data, such as estrogen receptor, progesterone receptor, Her2/neu status, tumor stage or grade.
\end{abstract}

Conclusions: GHET1 is possibly contributed in the pathogenesis of a fraction of breast cancers

Keywords: Long Non-Coding RNA, Breast Cancer, GHET1

\section{Background}

Breast cancer is the most frequently diagnosed cancer among women accounting for about one-third of all new cancers in women (1). The most common type of breast cancer is invasive ductal carcinoma, which accounts for $50 \%$ to $80 \%$ of all cases (2). Most breast cancers have been shown to be hormone receptor positive with $75 \%$ of them being estrogen receptor (ER) positive and 55\% being progesterone receptor (PR) positive (3). Although several treatment modalities have been designed for patients with breast cancer based on the expression of these markers, a significant number of patients do not benefit from these treatment strategies. Based on the heterogeneous nature of breast cancer, which incorporates numerous subgroups with variable molecular profiles, prognoses, and responses to therapies (4), several groups have aimed at identifying molecular targets with potentials to be used in therapeu- tic strategies. Although mRNA coding genes have been presented as special biomarkers (5-8) and therapeutic targets (9-12) for several years, non-coding RNAs have just recently attained attentions of researchers. A group of these transcripts, called as long non-coding RNAs (IncRNAs), have the length of more than 200 nucleotides, which differentiates them from classic non-coding RNAs, such as ribosomal (r)RNAs, ribozymes, transfer (t)RNAs, and microRNAs (13). In addition, they have been shown to participate in many central biologic processes comprising regulation of gene expression, telomere length, chromatin reorganization, histone alterations, genomic imprinting, and cell differentiation all of them being involved in cancer development $(14,15)$. We have previously evaluated the expression of a number of lncRNAs in breast cancer in relation to patients' clinical characteristics to determine the role of these transcripts in breast tumorigenesis $(16,17)$. In the present study, we aimed at identifying lncRNA-gastric carcinoma high ex-

Copyright (c) 2017, Cancer Research Center (CRC), Shahid Beheshti University of Medical Sciences. This is an open-access article distributed under the terms of the Creative Commons Attribution-NonCommercial 4.0 International License (http://creativecommons.org/licenses/by-nc/4.0/) which permits copy and redistribute the material just in noncommercial usages, provided the original work is properly cited. 
pressed transcript 1 (lncRNA-GHET1, AK123072) expression in breast cancer tissues compared with their adjacent noncancerous tissues (ANCT) in a cohort of Iranian patients. As its name implies, GHET1 has been firstly characterized as an IncRNA over-expressed and participated in the pathogenesis of gastric cancer (18). Subsequently, its contribution in the pathogenesis of bladder cancer has been revealed (19). However, to the best of our knowledge, there is no data regarding its expression in breast cancer tissues and its contribution in breast tumorigenesis.

\section{Methods}

\subsection{Tissue Samples}

The Ethical Committee of Shahid Beheshti University of Medical Sciences (Tehran, Iran) approved this study. Forty-seven samples of invasive ductal carcinoma of breast, in addition to their ANCTs, were obtained from patients in Sina and Farmanieh hospitals under the conventions of the ethics committee. ANCT was defined as the normal breast tissue and the diagnosis was confirmed by the pathologists through H.E. staining. Informed consent was obtained from all participants. The clinical and pathological data of patients were gathered through questionnaires and evaluation of medical records. The samples were instantly snap-frozen in liquid nitrogen before being stored in $-70^{\circ} \mathrm{C}$.

2.2. RNA Extraction and Quantitative Real-Time Reverse Transcription Polymerase Chain Reaction (RT-PCR)

The AccuZol ${ }^{\mathrm{TM}}$ total RNA extraction solution (Bioneer, Korea) was used for RNA extraction according to the manufacturer's instructions. A 1 hour treatment with DNase I has also been included. The purity, concentration, and integrity of RNA were analyzed by Thermo Scientific NanoDrop ${ }^{\mathrm{TM}} 1000$ Spectrophotometer and gel electrophoresis, respectively. Then, cDNA was synthetized from all samples, using $1 \mu \mathrm{g}$ of RNA in Primescript RT reagent kit (Takara Bio, Ohtsu, Japan). Synthesized cDNA was, then, checked spectrophotometrically to appraise its concentration. Quantitative RT-PCR reaction was performed on a rotor gene 6000 corbette detection system, using SYBR Premix Ex Taq (Takara Bio, Ohtsu, Japan). Thermal cycling conditions were an initial activation step for 5 minutes at $95^{\circ} \mathrm{C}$ followed by 40 cycles at $95^{\circ} \mathrm{C}$ for 15 seconds, specific annealing temperature for 15 seconds, and $72^{\circ} \mathrm{C}$ for 20 seconds. The specific annealing temperatures were $63^{\circ} \mathrm{C}$ for GHET1 and B2M and $56.5^{\circ} \mathrm{C}$ for MYC. No template control (NTC) containing $\mathrm{H}_{2} \mathrm{O}$ was included in each run. B2M gene was used as normalizer. Forward and reverse primers sequences are as follows, respectively: GHET1: 5'- AGTCAGCTCCCTACAGAGGTG3' and 5'-TCCTTAGGTGGTGGTTTCTGTTC-3'; B2M: 5'-AGATGAGTATGCCTGCCGTG-3' and 5'-GCGGCATCTTCAAACCTCCA-3'; MYC: 5'CACATCAGCACAACTACG-3' and 5'-GTTCGCCTCTTGACATTC3'. Melting curve analysis was carried out to validate specificity of PCR products. In addition, PCR products were electrophoresed on $2 \%$ agarose gel to verify product sizes and specificity.

2.3. Estrogen Receptor (ER), Progesterone Receptor (PR), Her2/neu, and Ki-67 Status

Patients' medical records were used for evaluation of these markers. In brief, all of these markers were assessed by immunohistochemical (IHC) staining. For ER and PR, staining of $>20 \%$ of tumor cell nuclei was considered positive. For Her2/neu, a test result of 0 to $2+$ was regarded as negative and $3+$ as positive. Ki-67 values were reported as both the percentage of positively stained malignant cells among the entire number of malignant cells and alternatively as positive vs. negative.

\subsection{Statistical Analysis}

Fold changes in gene expression were calculated by LinRegPCR (2) and relative expression software Tool-RG ${ }^{\circledR}$. version 3 (QIAGEN, Korea). The amplification efficiencies and cycle thresholds were used for such comparative quantification analysis. The quantities of mRNAs in the samples were normalized to the B2M mRNA and compared between paired tumor and ANCTs. The significant alterations in gene expression were determined by the pairwise fixed reallocation randomization test with 2000 iterations in the REST 2009 software. The level of statistical significance was set at $\mathrm{P}<0.05$.

Statistical analyses were executed by SPSSv.20 (SPSS Inc., Chicago, IL). The Wilcoxon signed-rank and McNemar tests were used when comparing paired tumor and ANCTs. Chi-square and independent t tests were used for testing the relationship between categorical variables. Significance was defined as $\mathrm{P}<0.05$.

\section{Results}

\subsection{General Statistical Information}

Breast tissues from a total of 47 female patients with breast cancer with the mean age of $51.35 \pm 14.721$ (23 - 84) were drawn from our previous study (16) and recruited in the current project. Clinicopathological data such as patients' age, tumor size, tumor stage and grade, ER, PR, Her2/neu, and Ki67 status have been investigated based on the evidences acquired from questionnaires, interviews, 
and clinical and laboratory tests as mentioned in the previous study (16).

Table 1. LncRNA-GHET1 Expression and its Associations with Patients' Clinical and Demographic Data

\begin{tabular}{|c|c|c|c|c|}
\hline Characteristics & Down Regulation & Up Regulation & No. & PValue \\
\hline Age & & & & 0.2 \\
\hline$<50$ & 17 & 8 & 25 & \\
\hline$\geq 50$ & 17 & 4 & 21 & \\
\hline Stage & & & & 0.147 \\
\hline 0 & 1 & 0 & 1 & \\
\hline I & 3 & 1 & 4 & \\
\hline II & 19 & 7 & 26 & \\
\hline III & 11 & 2 & 13 & \\
\hline IV & 0 & 2 & 2 & \\
\hline Histological grade & & & & 0.256 \\
\hline I & 4 & 2 & 6 & \\
\hline II & 20 & 4 & 24 & \\
\hline III & 9 & 6 & 15 & \\
\hline Family history & & & & 0.259 \\
\hline No & 23 & 10 & 33 & \\
\hline Yes & 11 & 2 & 13 & \\
\hline Tumor size, cm & & & & 0.194 \\
\hline$<2$ & 7 & 1 & 8 & \\
\hline$\geq 2,<5$ & 25 & 9 & 34 & \\
\hline$\geq 5$ & 1 & 2 & 3 & \\
\hline Node status & & & & 0.618 \\
\hline Negative & 20 & 7 & 27 & \\
\hline Positive & 14 & 5 & 19 & \\
\hline ER status & & & & 0.641 \\
\hline Negative & 9 & 24 & 33 & \\
\hline Positive & 3 & 8 & 11 & \\
\hline PR status & & & & 0.435 \\
\hline Negative & 12 & 3 & 15 & \\
\hline Positive & 21 & 8 & 29 & \\
\hline Her2/neu status & & & & 0.516 \\
\hline Negative & 25 & 9 & 34 & \\
\hline Positive & 8 & 2 & 10 & \\
\hline Ki67 status & & & & 0.578 \\
\hline Negative & 2 & 1 & 3 & \\
\hline Positive & 29 & 9 & 38 & \\
\hline Hormone replacement therapy & & & & 0.245 \\
\hline Negative & 26 & 11 & 37 & \\
\hline Positive & 8 & 1 & 9 & \\
\hline Body mass index & & & & 0.012 \\
\hline $18.5-24.9$ & 0 & 3 & 3 & \\
\hline $25-29.9$ & 20 & 5 & 25 & \\
\hline$>30$ & 13 & 4 & 17 & \\
\hline Smoking history & & & & 0.162 \\
\hline Negative & 33 & 10 & 43 & \\
\hline Positive & 1 & 2 & 3 & \\
\hline
\end{tabular}

\subsection{Expression of GHET1 and MYC in Patients' Samples}

Significant elevated GHET1 expression was identified in $13 / 47$ (26\%) of cancer tissue samples compared with their corresponding ANCTs. However, the comparison of GHET1 transcript levels between total tumor and ANCT tissues demonstrated a significant down-regulation in tumor tissues compared with ANCTs $(\mathrm{P}=0.02)$. Figure 1 shows the frequency and percentage of samples in certain subgroups based on relative expression of GHET1 in tumor tissues compared with ANCTs. No significant association has been found between the level of GHET1 transcripts and those of MYC $(\mathrm{P}=0.324)$.

\subsection{Correlations Between GHET1 Expression and Clinical Char- acteristics}

To further determine the role of GHET1 in breast cancer, we subsequently analyzed the associations between its transcript levels and numerous clinicopathological characteristics. However, no significant associations have been found between GHET1 expression and these features except for an association between GHET1 transcript level and body mass index. The relationship between GHET1 expression and clinicopathological variables is demonstrated in Table 1. Then, the patients were divided into 3 groups based on the relative GHET1 expression (REX) in tumor tissues compared with the corresponding ANCT: over-expressed (REX $>$ $1, \mathrm{n}=13)$, moderately down-regulated $(0.185<\mathrm{REX}<1, \mathrm{n}=$ 8 ), and highly down-regulated (REX $\leq 0.185, \mathrm{n}=26)$. The average level of REX in patients with GHET1 down-regulation was 0.185 , so this value was chosen for further categorization of patients. Statistical analyses performed for these 3 groups showed no significant association between GHET1 transcript levels and clinicopathological data. As the expression analyses have been performed on the same samples as our previous study, we further analyzed the associations between GHET1 expression and 2 other IncRNAs, whose expressions have been evaluated in the same samples previously by our group (16). A significant association has been found between GHET1 and CCAT2 expression ( $\mathrm{P}=$ 0.038), while no association was detected between the levels of GHET1 and aHIF transcripts $(\mathrm{P}=0.415)$.

\section{Discussion}

In the present study, for the first time we demonstrated GHET1 over-expression in $26 \%$ of samples with breast invasive ductal carcinoma relative to their paired ANCTs. Previous studies have shown many lncRNAs to be dysregulated during breast tumorigenesis. According to their expression pattern in tumor tissues and their putative function, they have been categorized into tumor suppressor and 


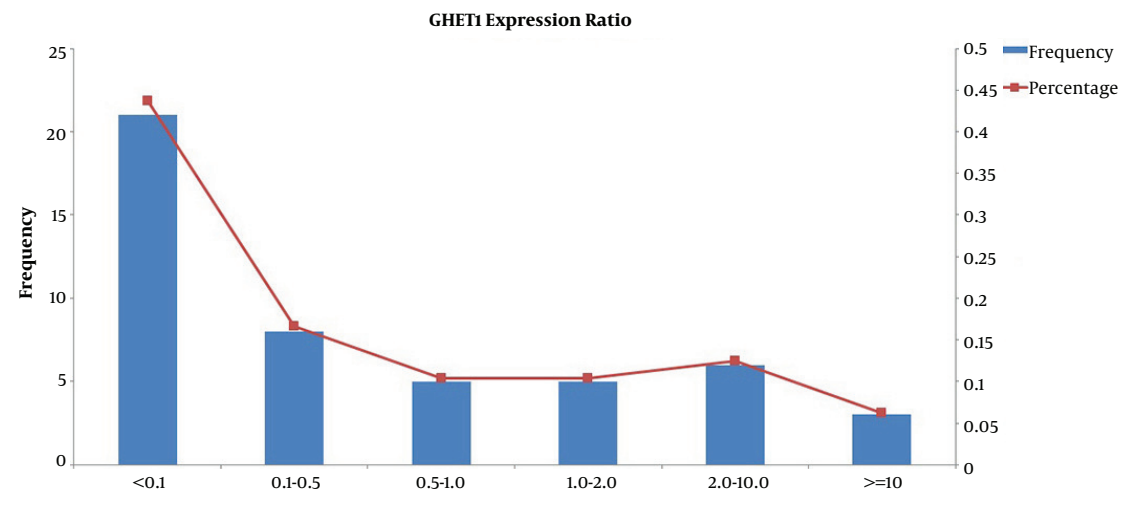

Figure 1. The Frequency and Percentage of Samples in Certain Subgroups Based; On relative expression of GHET1 in tumor tissues compared with ANCTs.

oncogene IncRNAs (14). Formerly, GHET1 has been shown to enhance the proliferation of gastric carcinoma cells in vitro and in vivo. Its function is probably mediated by increasing c-Myc mRNA stability and expression (18). In addition, GHET1 over-expression has been demonstrated in bladder cancer tissues compared to adjacent normal tissues and its transcript levels were correlated with tumor size, advanced stages, lymph node involvement, and poor prognosis. Its role in bladder cancer pathogenesis has been confirmed by loss-of- function analysis, which showed that it is involved in the proliferation and invasion of bladder cancer cells via regulation cell cycle checkpoints as well as the epithelial-mesenchymal-transition (19). Consequently, GHET1 can be regarded as an oncogene in these 2 types of cancer. In addition, GHET1 have been shown to directly interact with insulin-like growth factor 2 mRNA binding protein 1 (IGF2BP1) and have increased the physical interface between MYC mRNA and IGF2BP1 (18). Considering the role of GHET1 in regulation of MYC MRNA stability and expression via its interaction with IGF2BP1 (18), frequent MYC dysregulation in breast cancer (20) as well as expression of IGF2BP1 in breast cancer and its role in clonogenic growth of these cells (21), GHET1 was expected to participate in breast cancer pathogenesis as well. However, the results of the present study showed no consistent expression trend in samples with breast cancer examined. Furthermore, its transcript levels were neither correlated with prognostic markers nor with the MYC transcript levels. Future studies with larger sample sizes are needed to evaluate its significance in breast tumorigenesis. As the majority of non-protein-coding transcripts demonstrate cell-specific expression patterns (22), their putative role on the pathogenesis of distinct cancers might be different. However, there are certain IncRNAs, which have a similar function in the development of diverse cancers $(14,15)$. On the other hand, although we demonstrated the dys- regulation of GHET1 in breast cancer tissues, further functional analyses are needed to evaluate its precise role during breast tumorigenesis. Based on the genetic and epigenetic instabilities detected in tumoral tissues, it is possible that dysregulation of expression of many genes in these tissues are the simple by-product of stochastic situation caused by such instabilities. Consequently, in vitro loss-offunction and gain-of-function studies would facilitate the determination of GHET1 function during breast tumorigenesis.

\subsection{Conclusions}

Although previous studies have demonstrated GHET1 over-expression in gastric and bladder cancers and its contribution in the pathogenesis of both cancers, in the present study, we could detect its over-expression in only $26 \%$ of breast tumor samples.

\section{Acknowledgments}

This study was supported by a grant from Shahid Beheshti University of Medical Sciences and done as M.Sc. project of the first author. No conflict of interests exists.

\section{Footnotes}

Authors' Contribution: Shaghayegh Sarrafzadeh and Mohammad Taheri carried out the experiments. Lobat Geranpayeh provided the patients' samples and clinical data. Somayyeh Ghafouri-Fard performed the statistical analyses. Soudeh Ghafouri-Fard designed the study and wrote the manuscript. All authors read and approved the final manuscript.

Conflict of Interests: None declared.

Financial Disclosure: None declared. 


\section{References}

1. Siegel RL, Miller KD, Jemal A. Cancer statistics, 2015. CA Cancer J Clin. 2015;65(1):5-29. doi:10.3322/caac.21254.

2. Ghafouri-Fard S, Shamsi R, Seifi-Alan M, Javaheri M, Tabarestani S. Cancer-testis genes as candidates for immunotherapy in breast cancer. Immunotherapy. 2014;6(2):165-79. doi: 10.2217/imt.13.165. [PubMed: 24491090].

3. Tabarestani S, Motallebi M, Akbari ME. Are estrogen receptor genomic aberrations predictive of hormone therapy response in breast cancer?. Iran J Cancer Prev. 2016;9(4). doi: 10.17795/ijcp-6565.

4. Higgins MJ, Baselga J. Targeted therapies for breast cancer.JClin Invest. 2011;121(10):3797-803. doi: 10.1172/JCI57152. [PubMed: 21965336].

5. Dianatpour M, Mehdipour P, Nayernia K, Mobasheri MB, GhafouriFard S, Savad S, et al. Expression of Testis Specific Genes TSGA10, TEX101 and ODF3 in Breast Cancer. Iran Red Crescent Med J. 2012;14(11):722-6. doi: 10.5812/ircmj.3611. [PubMed: 23396665].

6. Seifi-Alan M, Shamsi R, Ghafouri-Fard S, Mirfakhraie R, Zare-Abdollahi D, Movafagh A, et al. Expression analysis of two cancer-testis genes, FBXO39 and TDRD4, in breast cancer tissues and cell lines. Asian Pac J Cancer Prev. 2014;14(11):6625-9. [PubMed: 24377578].

7. Rastgoosalami M, Memar B, Aledavood SA, Fanipakdel A. Evaluation of MAGE-1 Cancer-Testis Antigen Expression in Invasive Breast Cancer and its Correlation with Prognostic Factors. Iran J Cancer Prev. 2016;9(4). e4404. doi: 10.17795/ijcp-4404. [PubMed: 27761208].

8. Kazemi-Oula G, Ghafouri-Fard S, Mobasheri MB, Geranpayeh L, Modarressi $\mathrm{MH}$. Upregulation of RHOXF2 and ODF4 Expression in Breast Cancer Tissues. Cell J. 2015;17(3):471-7. [PubMed: 26464818].

9. Esfandiary A, Taherian-Esfahani Z, Abedin-Do A, Mirfakhraie R, Shirzad M, Ghafouri-Fard S, et al. Lactobacilli Modulate Hypoxia-Inducible Factor (HIF)-1 Regulatory Pathway in Triple Negative Breast Cancer Cell Line. Cell J. 2016;18(2):237-44. [PubMed: 27540529].

10. Taherian-Esfahani Z, Abedin-Do A, Nouri Z, Mirfakhraie R, GhafouriFard S, Motevaseli E. Lactobacilli Differentially Modulate mTOR and Wnt/ beta-Catenin Pathways in Different Cancer Cell Lines. Iran J Cancer Prev. 2016;9(3). e5369. doi: 10.17795/ijcp-5369. [PubMed: 27703648].

11. Esfandiary A, Ghafouri-Fard S. New York esophageal squamous cell carcinoma-1 and cancer immunotherapy. Immunotherapy. 2015;7(4):411-39. doi: 10.2217/imt.15.3. [PubMed: 25917631].
12. Esfandiary A, Ghafouri-Fard S. MAGE-A3: an immunogenic target used in clinical practice. Immunotherapy. 2015;7(6):683-704. doi: 10.2217/imt.15.29. [PubMed: 26100270].

13. Kung JT, Colognori D, Lee JT. Long noncoding RNAs: past, present, and future. Genetics. 2013;193(3):651-69. doi: 10.1534/genetics.112.146704. [PubMed: 23463798].

14. Soudyab M, Iranpour M, Ghafouri-Fard S. The Role of Long NonCoding RNAs in Breast Cancer. Arch Iran Med. 2016;19(7):508-17. [PubMed: 27362246].

15. Nikpayam E, Tasharrofi B, Sarrafzadeh S, Ghafouri-Fard S. The Role of Long Non-Coding RNAs in Ovarian Cancer. Iran Biomed J. 2017;21(1):315. doi: 10.6091/.21.1.24. [PubMed: 27664137].

16. Tasharrofi B, Soudyab M, Nikpayam E, Iranpour M, Mirfakhraie R, Sarrafzadeh S, et al. Comparative expression analysis of hypoxiainducible factor-alpha and its natural occurring antisense in breast cancer tissues and adjacent noncancerous tissues. Cell Biochem Funct. 2016;34(8):572-8. doi: 10.1002/cbf.3230. [PubMed: 27862063].

17. Iranpour M, Soudyab M, Geranpayeh L, Mirfakhraie R, Azargashb E, Movafagh A, et al. Expression analysis of four long noncoding RNAs in breast cancer. Tumour Biol. 2016;37(3):2933-40. doi: 10.1007/s13277015-4135-2. [PubMed: 26409453].

18. Yang F, Xue X, Zheng L, Bi J, Zhou Y, Zhi K, et al. Long non-coding RNA GHET1 promotes gastric carcinoma cell proliferation by increasing cMyc mRNA stability. FEBS J. 2014;281(3):802-13. doi: 10.1111/febs.12625. [PubMed: 24397586].

19. Li LJ, Zhu JL, Bao WS, Chen DK, Huang WW, Weng ZL. Long noncoding RNA GHET1 promotes the development of bladder cancer. Int JClin Exp Pathol. 2014;7(10):7196-205. [PubMed: 25400817].

20. Xu J, Chen Y, Olopade OI. MYC and Breast Cancer. Genes Cancer. 2010;1(6):629-40. doi: 10.1177/1947601910378691. [PubMed: 21779462].

21. Fakhraldeen SA, Clark RJ, Roopra A, Chin EN, Huang W, Castorino J, et al. Two Isoforms of the RNA Binding Protein, Coding Region Determinant-binding Protein (CRD-BP/IGF2BP1), Are Expressed in Breast Epithelium and Support Clonogenic Growth of Breast Tumor Cells. J Biol Chem. 2015;290(21):13386-400. doi:10.1074/jbc.M115.655175. [PubMed: 25861986].

22. Derrien T, Johnson R, Bussotti G, Tanzer A, Djebali S, Tilgner H, et al. The GENCODE v7 catalog of human long noncoding RNAs: analysis of their gene structure, evolution, and expression. Genome Res. 2012;22(9):1775-89. doi: 10.1101/gr.132159.111. [PubMed: 22955988]. 